\title{
Zulbainar: Perempuan Pejuang Masyarakat Marjinal sebagai Aktivis Gerwani (1961-1977)
}

\author{
Serli Agustina, Siti Fatimah \\ seliagustina171@gmail.com \\ Universitas Negeri Padang
}

\begin{abstract}
This article is a historical study that discusses the journey of life and experience of a Zulbainar woman who is a Gerwani (Gerakan Wanita Indonesia) from the Sungai Sariak district, Padang Pariaman Regency which is one of the base area of PKI and 'family' in west Sumatera. This research includes thematic biographical research with the purpose of the research to describe the journey of life, the role and experiences of Zulbainar in Gerwani at the Sungai Sariak district, Padang Pariaman Regency. This research uses the historical methods based on the four steps of activity of heuristic, source criticism, interpretation and historiography. The conclusion obtained is that this study expounded facts related to the events of the G30S in 1965 that occurred in West Sumatera. Zulbainar was one of the victims among the thousand of others who contributed to the eruption of G30S event in 1965. Her dedication to the forbidden organization had a huge impact on her life. Her enthusiasm for expanding the organization had left her branded a class B political prisoner. During the 12 years of imprisonment and their suffering ended in 1977. Her new status as a former political prisoner was enjoyed to this day in her twilight years. Today at the twilight of Zulbainar's age, actively voiced the determination of human rights for those affected by the G30S through a foundation called YPKP 1965 (Yayasan Korban Pembunuhan 1965) in West Sumatera.
\end{abstract}

Keywords: Gerwani, PKI, G30S 1965, political prisoner, Sungai Sariak

\begin{abstract}
Abstrak
Artikel ini merupakan kajian sejarah yang membahas mengenai perjalanan hidup dan pengalaman seorang Zulbainar yang merupakan perempuan Gerwani (Gerakan Wanita Indonesia) asal Sungai Sariak Kabupaten Padang Pariaman yang merupakan salah satu daerah basis PKI dan 'keluarganya' di Sumatera Barat. Penelitian ini termasuk penelitian biografi tematis dengan tujuan penelitian untuk mendeskripsikan perjalanan hidup, peran, serta pengalaman-pengalaman Zulbainar dalam Gerwani di Nagari Sungai Sariak. Penelitian ini menggunakan metode sejarah yang bertumpu pada empat langkah kegiatan yaitu heuristik, kritik sumber, interpretasi, dan historiografi. Kesimpulan dari penelitian mengungkapkan bahwa Zulbainar merupakan salah satu korban diantara ribuan korban dampak meletusnya G30S 1965. Keikutsertaannya dalam organisasi tersebut membawa dampak besar dalam hidupnya. Kiprahnya ikut gencar dalam mengembangkan organisasi membuatnya dicap sebagai tahanan politik golongan B. Selama 12 tahun dipenjara dan penderitaan baru berakhir tahun 1977. Status baru sebagai eks-Tapol dia nikmati hingga kini di usia senjanya. Sekarang Zulbainar aktif menyuarakan penengakkan HAM bagi mereka yang menjadi korban G30S 1965
\end{abstract}


melalui sebuah Yayasan yang bernama YPKP 1965 (Yayasan Penelitian Korban Pembunuhan 1965) Sumatera Barat.

Kata Kunci: Gerwani, PKI, G30S 1965, Tahanan Politik, Sungai Sariak

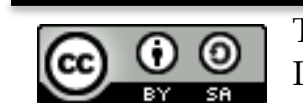

This work is licensed under the Creative Commons Attribution-ShareAlike 4.0 International License.

\section{Pendahuluan}

Organisasi Gerakan Wanita Indonesia atau yang lebih dikenal dengan Gerwani adalah organisasi wanita terbesar dalam sejarah gerakan wanita di Indonesia (Ahdiah, 2013). Organisasi yang berdiri pada tahun 1950 atas prakarsa S.K. Trimurti bersama beberapa pejuang wanita, terutama yang pernah melakukan geriliya pada Agresi Militer Kedua. Perkembangan cabang-cabang Gerwani tidak terlepas dari upaya pengkaderan yang menjadi "urat nadi" organisasi tersebut. Di Minangkabau Gerwani pun berkembang, meskipun dari sisi gagasannya banyak ditentang karena dianggap organisasi sayap PKI. Pada masa-masa awal, pimpinan Gerwani di Sumatera Barat adalah Nur Suhud dan Dahliar, masing-masing dari Padang Panjang dan Payakumbuh dan pusatnya di Lambau, Bukittinggi (Nuryanti, 2011).

Salah satu masalah paling mendesak yang dihadapi Gerwani dan menimbulkan diskusi-diskusi hangat dikalangan pimpinan pusat adalah persoalan "otonomi" organisasi dalam hubungannya dengan PKI yang lebih spesifik pada kejadian-kejadian dramatis sesudah Oktober 1965. Meskipun demikian, secara resmi Gerwani tidak pernah berafiliasi dengan PKI (Sakia Eleonora Wieringa \& Setiawan), 1999). Pasca peristiwa G30S, tuduhan semakin gencar yang diiringi dengan propaganda yang ditujukan kepada PKI dan organisasi massa PKI. Propaganda tersebut memicu terjadinya pengejaran, penangkapan, pembunuhan, dan pelecehan seksual terhadap anggota-anggota PKI dan organisasi massanya. Hal ini terjadi di banyak daerah di Indonesia, termasuk di Sumatera Barat. Tindak kekerasan tersebut menelan ratusan ribu korban. Sebagian mereka terbunuh dan sebagian lainnya selamat, namun hidup dalam kebijakan isolasi sosial, ekonomi dan politik pemerintahan rezim orde baru (Wahyuni, 2010).

Salah seorang korban peristiwa G30S yang terjadi di Sungai Sariak bernama Zulbainar. Dia adalah mantan anggota Gerwani Padang Pariaman yang pada masa aktifnya pernah menjabat sebagai bendahara umum di Gerwani Padang Pariaman. Zulbainar termasuk dalam tahanan politik golongan B dan dibebaskan pada tahun 1977. Sejak dibebaskan kini dia hidup dengan status baru sebagai eks-tapol. Pada saat pemburuan terjadi, suami Zulbainar bernama Syamsuddin yang juga merupakan 
anggota aktif PKI ikut ditangkap dan dibunuh dengan cara dipenggal oleh massa antiPKI tersebut (Zulbainar, 2018). Zulbainar dan teman-teman Gerwani lainnya bernasib mujur karena langsung diamankan ke kantor Polsek Sungai Sariak untuk diinterogasi. Setelah diintrogasi, Zulbainar beserta puluhan teman-teman Gerwaninya dipenjarakan selama 12 tahun tanpa peradilan.

Selama 12 tahun lamanya Zulbainar dan tahanan politik lainnya merasakan betapa pahitnya hidup dalam penjara, meninggalkan keluarga, anak dan suami mereka. Keadaan penjara yang sangat tidak manusiawi hari demi hari mereka rasakan, dalam ruangan kecil yang diisi 40 orang. Tekanan mental menjadi hal yang dirasakan bahkan kekerasan fisik dalam penderitaan mereka. Tidak hanya itu, bahkan setiap malam hari satu persatu dari mereka di ' $b$ on' $^{\prime}$ yang artinya dijemput dan tidak dikembalikan lagi (dibunuh). Stigma negatif dibangun pemerintah orde baru terhadap komunisme sebagai ideologi, PKI sebagai partai, serta kepada anggota-anggotanya. Banyak peraturan yang dibuat pemerintaah untuk mendukung adanya kampanye "awas bahaya laten". Masyarakat menganggap bahwa komunis akan bangkit kembali, sehingga para eks Tapol tersebut diberi aturan khusus oleh pemerintah yang harus mereka patuhi jika ingin tetap hidup berdampingan dalam masyarakat.

Ada beberapa kajian mengenai Gerwani yang telah ditulis oleh beberapa peneliti, seperti Saskia Wieringa yang menulis tentang kuntilanak wangi yang diterjemahkan dari judul aslinya The Perfumed Nightmare. Dalam karyanya Saskia Wieringa memfokuskan pada masalah organisasi perempuan di Indonesia terutama Gerwani. Selanjutnya, buku yang berjudul perempuan berselimut konflik karya Reni Nuryanti yang didalamnya mengkaji tentang perempuan Minangkabau di masa Dewan Banteng dan PRRI. Dalam kajiannya tersebut lengkap menjelaskan tentang aktivitas Gerwani di Sumatera Barat. Kajian lainnya adalah karya Amurwati Dwi Lestariningsih (2011) tentang kisah tapol Gerwani di kamp Plantungan yang menjelaskan kepahitan hidup yang dialami tapol perempuan yang diisolasi dan sarat dengan tindak kekerasan fisik maupun mental. Semua penelitian tersebut sangat penting dan menjadi landasan dalam menganalisis dalam artikel ini. Karya-karya mereka memperlihatkan sisi lain dari gerakan yang selama ini tidak dilirik dengan baik. Kajian mereka sangat mendukung dalam penelitian ini, yang memfokuskan pada kearifan lokal. Dalam artikel ini pembicaraan tentang Zulbainar, yang merupakan pelaku sejarah yang mempunyai banyak pengalaman-pengalaman penting dalam perjalanan hidupnya selama menjadi anggota Gerwani (Marta, 2018). 


\section{Metode Penelitian}

Penelitian ini termasuk penelitian biografi tematis karena mengkaji tentang kiprah dan pengalaman penting Zulbainar dalam Gerwani. Penelitian ini menggunakan metode sejarah yang bertumpu pada empat langkah kegiatan yaitu heuristik, kritik sumber, interpretasi, dan historiografi. Pada tahap heurik, mengumpulkan berbagai sumber sejarah yang berkaitan dengan topik penelitian berupa sumber primer dan sekunder. Sumber primer yang digunakan berupa data hasil wawancara dengan Zulbainar dan beberapa orang terdekat Zulbainar seperti Nadiani.S (Ketua YPKP 1965 Sumatera Barat), Manismar (eks Gerwani), dan Susi (Sekretaris YPKP Padang Pariaman). Selain itu, data jumlah korban peristiwa G30S di Sumatera Barat dan beberapa data lainnya.

Sumber sekunder yang digunakan berupa telaah kepustakaan yang berkenaan dengan kajian tentang Gerwani diantaranya buku karangan Reni Nurhayanti menulis tentang perempuan Minangkabau di masa Dewan Benteng dan PRRI. Selain itu, buku karangan Amurwati Dwi Lestariningsih (2011) yang mengkaji tentang tapol wanita di kamp. Plantungan. Tahap kritik sumber, dalam kritik sumber membandingkan beberapa hasil wawancara yang telah diperoleh. Tahap interpretasi, pada tahap ini dilakukan penafsiran dari sumber yang telah di kritik. Fakta-fakta tersebut disusun berdasarkan tahap klasifikasi masalah penelitian. Tahapan selanjutnya menghubungkan data yang diperoleh dari hasil wawancara, dokumen, studi pustaka dan studi arsip. Tahap historiografi, fase akhir melakukan penulisan sejarah ilmiah berdasarkan pada fakta-fakta yang telah disusun sesuai klasifikasi data dan kaidah-kaidah dalam penulisan sejarah (Abdurahman, 2007).

\section{Hasil dan Pembahasan}

\section{Lingkungan Sosial, Budaya dan Ekonomi Sungai Sariak}

Berlandasan Adat basandi syarak, syarak basandi kitabullah, Minangkabau menjadi suku terbesar di dunia yang memegang sistem kekerabatan matrilineal. Penempatan perempuan sebagai pusat pada adat matrilineal didukung oleh ajaran Islam sebagai contoh dinyatakan bahwa Surga di bawah telapak kaki ibu. Perempuan Minangkabau dalam pengakuan starata adat Minangkabau memiliki kedudukan yang tinggi, sebutan sebagai Bundo Kanduang melambangkan sebagai sosok perempuan yang cerdas, arif dan bijaksana. Hal ini tercermin dalam pepatah adat seperti: “Bundo limpapeh rumah nan gadang" (ibu berfungsi sebagai penyanggah), umbui parui pegangan kunci (pemegang kunci harta kekayaan), umbui dalam titah (sumber segala titah), sumarak dalam kampuang (penyemarak dalam suatu kampung) dan hiasan dalam nagari (hiasan negeri) (Fatimah, 
2012). Ungkapan pepatah ini bermakna bahwa perempuan Minangkabau memiliki peranan penting yang tidak bisa ditepiskan dalam adat Minangkabau.

Perempuan Minangkabau pada awal abad ke 20 telah mampu berkarya dengan bergerak pada bidang yang berbeda, seperti Rohana Kudus dan Rahmah El Yunusiyah yang telah membangun sekolah (M. dkk Zed, 1998). Perkembangan ilmu pengetahuan dan pendidikan telah mengubah pola fikir kaum perempuan Minangkabau untuk menjadi bagian dari masyarakat yang mampu memberi kontribusi terhadap kemajuan nagari. Hal ini yang menjadi salah satu faktor pendukung berkembangnya organisasiorganisasi perempuan di Sumatera Barat, salah satunya adalah Gerwani (Gerakan Wanita Indonesia). Perkembangan Gerwani dari pusat ke daerah berkembang pesat. Salah satu daerah yang menjadi basis Gerwani dan organisasi massa PKI adalah Nagari Sungai Sariak, Kabupaten Padang Pariaman. Sungai sariak dijuluki "Nagari Sirah" karena merupakan daerah di Kabupaten Padang Pariaman yang memiliki massa PKI dan Gerwani cukup banyak di bandingkan daerah-daerah di Sumatera Barat lainnya. Hal ini terbukti dari data korban peristiwa G30S di Kabupaten Padang Pariaman yang diperoleh dari YPKP 1965. Kecamatan VII Koto Sungai Sariak merupakan kecamatan dengan korban terbanyak dari 8 kecamatan yang ada di Kabupaten Padang Pariaman dengan jumlah korban dibunuh/diculik/dihilangkan sebanyak 132 orang, ditahan lapor sebanyak 4.162 orang, dan dibebaskan sebanyak 3.8887 orang. (lihat tabel 2, hlm 8).

Masyarakat Sungai Sariak rata-rata memiliki mata pencarian di bidang pertanian. Sawah, ladang, dan kebun adalah ranah bagi mereka untuk mengais rezeki. Kehidupan ekonomi yang mengandalkan hasil pertanian tentunya sangat bergantung dengan kondisi alam, sehingga masyarakat tidak bisa menentukan penghasilan tetap setiap bulan, terkadang untung atau rugi. BTI (Barisan Tani Indonesia) yang juga merupakan organisasi sayap PKI bekerja sama dengan Gerwani untuk memperjuangkan nasib para petani di Sungai Sariak. BTI dan Gerwani selain mendukung program pemerintah soal reforma agraria , BTI dan Gerwani juga turun langsung menemui kelompok-kelompok tani untuk memberikan pengajaran kepada mengajak masyarakat untuk memanfaatkan lahan tidur maupun berkebun di pekarangan rumah seperti menanam tumbuhan kebutuhan dapur untuk di konsumsi. Hal ini mengajarkan kepada para petani apa yang harus dibeli dan apa yang harus ditanam. Kondisi lingkungan ini relevan dengan isu yang dikemukakan oleh Gerwani.

\section{Pendidikan dan lingkungan keluarga Zulbainar}

Zulbainar lahir pada tanggal 17 Agustus 1939 di Nagari Sungai Sariak, Kecamatan VII Koto Sungai Sariak, Kabupaten Padang Pariaman dari pasangan H.Ilyas dan Bani 
Hamin. Anak kedua dari lima bersaudara perempuan. Saudara-saudaranya bernama Zulbaidar, Zulbaiyar (Alm), Zulmalis, dan Zulbainur (Alm). Lahir dan dibesarkan masa kolonial Belanda dan pendudukan Jepang membuat Zulbainar menjadi saksi yang turut merasakan bagaimana silih bergantinya pemerintahan di Indonesia. Kepahitan hidup di zaman kolonial, penderitaan zaman penjajahan Jepang, keganasan orde baru hingga zaman Revolusi saat ini di rasakannya. Bagi Zulbainar kepahitan hidup membentuknya menjadi pribadi yang kuat dan tegas hingga saat ini. Sikap tegas dan pemberaninya diturunkan dari sang ayah yang merupakan salah satu rakyat yang ikut berjuang melawan kolonial Belanda di Kabupaten Padang Pariaman, sehingga ayahnya selalu mendukung kegiatan Zulbainar untuk berjuang melalui organisasi-organisasi yang diikutinya. Ayahnya selalu berpesan kepada Zulbainar dan saudara-saudaranya walaupun mereka tidak mempunyai saudara laki-laki akan tetapi mereka harus tegas dan kuat seperti lelaki. Pada usia 21 tahun (1960) Zulbainar memutuskan untuk menikah dengan seorang pensiunan tentara bernama Bakaruddin, akan tetapi penikahan itu tidak berlangsung lama akibat suaminya meninggal dunia karena sakit. Dalam hidupnya Zulbainar telah menikah sebanyak lima kali akan tetapi, dia tidak memperoleh anak dari ke lima pernikahannya tersebut.

Kehidupan ekonomi yang sederhana dan hanya seorang gadis kampung tidak meredamkan api semangat Zulbainar untuk sekolah. Berbeda dengan anak perempuan seusianya yang hanya pasrah akan nasib bahwa sekolah tidakl diwajibkan untuk kaum perempuan. Zulbainar menempuh jenjang pendidikan dasar di SR Koto Mambang, Kab. Padang Pariaman selama enam tahun dan menjadi satu-satunya perwakilan SR tersebut untuk melanjutkan ke jenjang berikutnya. Zulbainar melanjutkan sekolahnya di SKP Kota Padang (Sekolah Kepandaian Putri) selama 3 tahun, setelah tamat dari SKP kemudian meneruskan pendidikannya di SGKP (Sekolah Guru Kepandaian Putri) selama tiga tahun. Setelah lulus dari SGKP, Zulbainar mengajar di beberapa sekolah seperti TK Gadih Rantih, Sekolah Agama Perti, dan di SR Koto Mambang (Julius, 2007). Meletusnya peristiwa G30S menjadi malapetaka yang mengakhiri segala impian yang telah dibangun oleh Zulbainar. Pemburuan terhadap anggota Gerwani dan organisasi massa PKI gencar dilakukan, tidak memandang apapun latar belakang mereka termasuk Zulbainar yang pada saat itu merupakan seorang guru. Zulbainar tertangkap dan SK mengajarnya pun dicabut oleh pemerintah untuk selamanya.

\section{Zulbainar dalam Gerwani}

Perkembangan Gerwani di Kabupaten Padang Pariaman sejalan dengan perkembangan PKI yang sangat pesat pada saat itu terutama di Nagari Sungai Sariak. Sungai Sariak menjadi salah satu basis PKI dan organisasi massanya teermasuk 
Gerwani dengan anggotanya terbanyak di Sumatera Barat. Pada tahun tersebut Gerwani sedang Gencar melebarkan sayapnya di berbagai daerah untuk menggemakan beberapa hal pokok yang ingin dicapai Gerwani pada saat itu. Pertama, Gerwani ingin memimpin gerakan yang luas; kedua, ingin menjadikan Gerwani sebagai gerakan massa; ketiga, menghendaki agar gerakan perempuan memainkan perannya di kancah politik (Saskia Eleonora Wieringa, 1999). Pengkaderan adalah hal yang menjadi urat nadi dalam Gerwani. Perkembangan Gerwani sangat berkembang pesat dari pusat ke berbagai daerah termasuk di Sungai Sariak.

Perkenalan Zulbainar dengan Gerwani berawal pada saat kegiatan pemberantasan buta huruf bagi kaum perempuan sekaligus pengkaderan anggota di Sungai Sariak yang diadakan oleh Gerwani Kabupaten Padang Pariaman. Zulbainar masuk sebagai anggota Gerwani sekitar tahun 1954/1955 setelah lulus SR (Sekolah Rakyat) saat itu dia berusia 15 tahun. Zulbainar merasa tertarik dengan kegiatan-kegiatan dan tujuan dari Gerwani yang dijelaskan pada saat pengkaderan tersebut. Menurut Zulbainar ideologi Gerwani sangat cocok dengan pemikirannya, seperti anti poligami, anti kawin paksa, dan anti kawin dibawah umur, karena menurutnya gerakan ini sangat dibutuhkan oleh perempuan Minangkabau pada saat itu (Yati, 2017). Bagi Zulbainar sistem Minangkabau pada saat itu terkesan feodal karena banyak para datuk-datuk petinggi adat yang mempunyai harta dan tahta melakukan poligami bahkan hingga beristri empat layaknya raja-raja zaman dahulu. Menurutnya yang menjadi korban adalah perempuan dan anak. Oleh karena itu, melalui Gerwani Zulbainar ikut memperjuangkan hak-hak kaum perempuan agar tidak lagi menjadi korban dalam praktek poligami tersebut.

Resmi menjadi anggota, maka Zulbainar memulai kiprahnya di Gerwani. Bersama dengan anggota lainnya, dalam kegiatan-kegiatan pengkaderan dan pemberantasan buta huruf di lingkungan sekitar Kecamatan VII Koto Sungai Sariak. Namun Zulbainar tidak bisa meneruskan kegiatan tersebut karena harus melanjutkan pendidikannya di SKP Kota Padang. Akan tetapi Zulbainar tidak memutuskan perjuangannya, dia meneruskan kiprah Gerwaninya di Gerwani cabang Kota Padang bersama dengan anggota lainnya yang juga merupakan pelajar dari berbagai daerah di Sumatera Barat. Setiap pulang sekolah selalu berkumpul di kantor Gerwani cabang Kota Padang untuk merancang kegiatan-kegiatan yang menjadi program rutin setiap minggunya.

Setelah lulus sekolah di SGKP Kota Padang Zulbainar memutuskan pulang kampung ke Sungai Sariak dan melanjutkan perjuangannya di Gerwani Sungai Sariak. Melihat kepandaian Zulbainar dalam berpidato dan berbicara dan didukung dari pengalamanpengalamannya di Gerwani cabang Kota Padang membuat Zulbainar dilirik untuk menjadi pengurus di Gerwani tingkat Kabupaten Padang Pariaman dengan jabatan 
sebagai bendahara umum. Sebagai seorang pengurus inti Zulbainar lebih berfokus pada perkembangan organisasi tersebut. Walau jabatan sebagai bendahara akan tetapi ia tetap ikut dalam kegiatan-kegiatan lapangan karena baginya hal itu adalah salah satu keahliannya yaitu sebagai seorang guru.

\section{Zulbainar dalam Belitan Peristiwa G30S (Ditangkap dan dibebaskan)}

Berbagai media massa menyiarkan bahwa adanya keterlibatan wanita dalam kejadian pembunuhan para jenderal pada 30 September 1965 yang terjadi di Lubang buaya. Menurut berita yang dimuat dalam harian Angkatan Bersendjata dan Berita Yudha anggota-anggota Gerwani dengan bertelanjang dan menari-nari "harum bunga" dan memotong alat vital para jenderal sebelum dimasukan ke sebuah sumur di Lubang Buaya. Tuduhan terhadap PKI dan organisasi massa dimulai oleh Mayor Soeharto yang secara tidak langsung menyebutkan bahwa anggota Pemuda Rakyat dan anggota Gerwani yang merupakan organisasi massa PKI terlibat dalam pembunuhan para jenderal tersebut (Marta, 2018). Para ahli forensik, yang memeriksa mayat-mayat itu sesudah diangkat dari sumur, tidak mendapati bekas luka seperti yang dituduhkan (Sakia Eleonora Wieringa \& Setiawan), 1999). Kombinasi propaganda dan tuduhan yang dibuat oleh media dan Angkatan Darat pada saat itu berhasil gilang gemilang hingga masih dipercaya masyarakat Indonesia sampai saat ini. Fitnah dan propaganda media massa tersebut mengakibatkan Gerwani dan seluruh organisasi massa PKI lainnya menjadi organisasi terlarang karena dituduh sebagai dalang pada peristiwa G30S (Kahin, 2008).

Histeria dan kemarahan masyarakat berujung pada pemburuan seluruh anggota Gerwani dan organisasi massa PKI lainnya. Pemburuan tersebut tidak hanya terjadi di Jawa, dampaknya bahkan sampai diseluruh daerah yang memiliki cabang Gerwani termasuk di Sumatera Barat. Pemburuan dilakukan dengan berbagai cara seperti penangkapan, pemerkosaan, penyiksaan bahkan langsung dibunuh di tempat tanpa megnetahui mereka bersalah atau tidak. Pemburuan oleh massa gencar dilakukan, hal tersebut tidak terelakan oleh Zulbainar dan teman-temannya. Keadaan Sungai Sariak yang tidak kondusif membuat Zulbainar, suami dan teman-temannya memutuskan untuk sementara menjauhkan diri dari Sungai Sariak sampai kondisi aman. Belum jauh meninggalkan Sungai Sariak, Zulbainar dan rombongan dikepung dan tertangkap oleh massa. Saat itu terjadi salah satu kisah tragis dalam hidup Zulbainar, ia harus kehilangan suami yang dicintainya yang dibunuh dengan cara dipenggal kepalanya oleh massa anti komunis pada saat itu (Robert, 2010). Saat suaminya dibawa oleh massa, Zulbainar dan teman-teman lainnya dibawa ke polsek untuk diintrogasi terkait keterlibatan dalam Gerwani. Ketika di polsek Zulbainar dikejutkan dengan massa yang 
membawa kepala suaminya kemudian mereka lemparkan kepala tersebut ke kaki Zulbainar. Dengan hati yang tegar dan penuh kehancuran Zulbainar meminta tolong kepada polisi untuk mencarikan kain kafan dan menguburkan kepala suaminya tersebut dengan baik.

Setelah proses interogasi selesai Zulbainar dan teman-teman Gerwaninya ditahan di Polsek Sungai Sariak dan kemudian dipindahkan ke LPM Makodim Polres di Pariaman. 12 tahun lamanya Zulbainar dan tapol lainnya merasakan kepedihan hidup di penjara. Setiap hari mereka hanya bisa berdoa agar masih bisa hidup esok hari, karena tidak ada yang menjamin keselamatan mereka, sebab setiap malam salah seorang tapol akan di bon atau hilang malam (dibunuh) (Mestika Zed, 2010). Adapun data korban G30S di Sumatera Barat adalah sebagai berikut :

Tabel 1. Data Korban Peristiwa G30S di Prov. Sumatera Barat

\begin{tabular}{|c|c|c|c|c|}
\hline No & Daerah & $\begin{array}{c}\text { Korban yang } \\
\text { dibunuh }\end{array}$ & $\begin{array}{l}\text { Ditahan / lapor } \\
\text { diri }\end{array}$ & $\begin{array}{l}\text { Korban } \\
\text { Keluarga } \\
\text { Masih hidup }\end{array}$ \\
\hline 1. & $\begin{array}{l}\text { Padang Pariaman/ } \\
\text { Pariaman }\end{array}$ & 387 & 9.450 & 49.1865 \\
\hline 2. & Pesisir Selatan & 1.013 & 1.889 & 11.608 \\
\hline 3. & Agam & 13 & 2.412 & 9.700 \\
\hline 4. & Padang & 15 & 1.500 & 7.575 \\
\hline 5. & Tanah Datar & 65 & 4.038 & 20.515 \\
\hline 6. & 50 Kota/ Payakumbuh & 756 & 4.580 & 28.180 \\
\hline 7. & Kab. Solok/Solok & 11 & 1.239 & 6.500 \\
\hline 8. & Sawah Lunto/ Sijunjung & 7 & 1.858 & 9.325 \\
\hline 9. & Padang Panjang & 10 & 189 & 995 \\
\hline 10. & Pasaman & 51 & 3.957 & 12.432 \\
\hline & Jumlah & 2.277 & 30.212 & 135.500 \\
\hline
\end{tabular}

Sumber : YPKP (Yayasan Korban Pembunuhan) 1965/1966 Sumatera Barat

Tabel 2. Data Korban Peristiwa G30S di Kabupaten Padang Pariaman

\begin{tabular}{llllll}
\hline No & Kecamatan & $\begin{array}{l}\text { Dibunuh/ } \\
\text { diculik/ } \\
\text { dihilangkan }\end{array}$ & $\begin{array}{l}\text { Ditahan } \\
\text { Lapor }\end{array}$ & $\begin{array}{l}\text { Keluarga } \\
\text { Korban }\end{array}$ & Dibebaskan \\
\hline 1. & VII Koto Sungai Sariak & 132 & 4.162 & 21.470 & 3.887 \\
\hline 2. & 2x 11 Enam Lingkung & 114 & 3.436 & 17.750 & 3.376 \\
\hline 3. & Nan Sabaris & 49 & 502 & 2.755 & 392 \\
\hline 4. & V Koto & 43 & 397 & 2.200 & 369 \\
\hline 5. & S. Geringging & 20 & 218 & 1.190 & 164 \\
\hline 6. & Lubuk Alung & 15 & 364 & 1.895 & 339 \\
\hline 7. & Sungai Limau & 9 & 304 & 1.565 & 242 \\
\hline 8. & Pariaman & 5 & 67 & 360 & 6 \\
\hline & Jumlah & 387 & 9.450 & 49.185 & 8.830 \\
\hline
\end{tabular}

Sumber : YPKP (Yayasan Korban Pembunuhan) 1965/1966 Sumatera Barat 
Seperti data diatas, Kec. VII Koto Sungai Sariak merupakan kecamatan dengan korban terbanyak di Kabupaten Padang Pariaman, karena 80\% masyarakat Sungai Sariak merupakan anggota PKI dan organisasi sayap PKI lainnya, sebagian besar ibuibu dan remaja perempuan di Sungai sariak adalah anggota Gerwani. Penderitaan akhirnya berakhir pada tahun 1977. Pembebasan tapol golongan B dan C dilakukan pada masa kepemimpinan Gubernur Sumatera Barat Prof. Drs. H. Sutan Harun A. Rasjid Zain (Harun Zain). Pada hari itu seluruh tapol diperintahkan bersiap-siap berangkat untuk berkumpul di lapangan Imam Bonjol Kota Padang untuk mendengarkan surat keputusan dari pemerintah pusat yang dibacakan oleh Gubernur Sumatera Barat Prof. Harun Zain mengenai pembebasan para tahanan politik. Surat berisikan keputusan pemerintah pusat untuk membebaskan dan mengembalikan tapoltapol tersebut ke masyarakat dan ke kampung halamannya masing-masing dan sejak saat itu mereka dinyatakan tidak lagi terlibat dengan PKI dan organisasi massanya. Tahun 1977 menjadi tahun yang sangat bersejarah dalam kehidupan Zulbainar dan tapol lainnya. Kebebasan yang didambakan oleh mereka selama ini pun akhirnya terwujud.

Zulbainar dan teman-temannya memulai hidup baru di kampung halamannya dengan status baru sebagai bekas tahanan politik (eks Tapol G30S/PKI). Status sebagai eks Tapol menjadi beban tersendiri, mereka harus kehilangan pekerjaan sebelumnya, bahkan deskriminasi dari pekerjaan yang berhubungan dengan pemerintahan seperti PNS, guru, pegawai Telkom dll. Walau sudah dinyatakan tidak lagi terlibat dalam organisasi terlarang, akan tetapi stigma negatif sebagai bekas tahanan masih melekat pada jati diri mereka dan keluarga mereka. Hal ini terbukti dengan adanya beragam peraturan khusus yang dibuat oleh pemerintah orde baru terhadap eks tapol maupun keluarga besar mereka yang harus mereka patuhi. Seperti yang dialami oleh Zulbainar, dia harus kehilangan pekerjaan yang sangat dicintai yaitu sebagai seorang guru. Saat sekolah di SKP Zulbainar banyak mendapatkan keterampilan, dengan keterampilan menjahit dan memasak yang akhirnya menopang perekonomian Zulbainar. Kini di usianya yang sudah senja tidak mengurangi semangat perjuangan Zulbainar. Hingga kini Zulbainar dan teman teman eks tapol lainnya aktif dalam menyuarakan penegakan HAM bagi mereka yang menjadi korban "salah tangkap" dalam peristiwa G30S 1965 melalui Yayasan Penelitian Korban Pembunuhan 1965 (YPKP 1965) Sumatera Barat yang berpusat di Bukittinggi (Andriani, 2015).

\section{Simpulan}

Kemarahan massa tersebut berujung pada pemburuan terhadap seluruh anggota Gerwani dan organisasi massa PKI lainnya diseluruh Indonesia. Zulbainar merupakan 
salah satu anggota aktif di Gerwani cabang Kab. Padang Pariaman yang juga ikut menjadi korban pemburuan. Zulbainar dan teman-teman Gerwani lainnya ikut tertangkap dan dipenjarakan selama 12 tahun hingga pada akhirnya dibebaskan dan dikembalikan ke masyarakat pada tahun 1977. Sejak dikembalikan ke masyarakat Zulbainar dan teman-temannya menjalani hidup dengan status baru yaitu sebagai ekstapol dengan berbagai peraturan khusus yang harus mereka patuhi. Sekarang Zulbainar

aktif dalam YPKP 1965 untuk menyuarakan penegakan HAM bagi mereka yang menjadi korban ‘salah tangkap' dalam peristiwa G30S/PKI 1965.

\section{Daftar Rujukan}

Abdurahman, D. (2007). Metodologi Penelitian Sejarah. Ar-Ruz Media.

Ahdiah, I. (2013). Peran-Peran Perempuan dalam Masyarakat. Jurnal Academica FISIP UNTAD, 5 (2).

Andriani, W. (2015). Gerwani di Bukittinggi 1957 sampai Pasca Peristiwa G30S. Universitas Negeri Padang.

Fatimah, S. (2012). Gender dalam komunitas masyarakat Minangkabau; Teori, praktek dan ruang lingkup kajian. Kafaah: Journal of Gender Studies, 2(1), 11-24.

Julius. (2007). Mambangkik Batang Tarandam. CV.Arena Seni.

Kahin, A. (2008). Dari Pemberontakan ke Integrasi,Sumatera Barat dan Politik Indonesia 19261998. Yayasan Obor Indonesia.

Lestariningsih, A. D. (2011). Gerwani: kisah tapol wanita di Kamp Plantungan. PT Gramedia Pustaka Utama.

Marta, S. (2018). Manismar: Gerwani di Bukittinggi (1995 2016). x. Universitas Negeri Padang.

Nuryanti, R. (2011). Perempuan berselimut konflik: Perempuan Minangkabau di masa Dewan Banteng dan PRRI. Tiara Wacana.

Robert, B. (2010). Nasib Keluarga PKI di Nagari Sungai Sariak Pasca G30S/PKI 1965. Universitas Negeri Padang.

Wahyuni, R. (2010). Zainar : Biografi seorang aktivis Gerakan Wanita Indonesia (GERWANI) di Sungai Sariak Kabupaten Padang Pariaman Tahun 1958-2008. Skripsi. Jurusan Sejarah UNAND. Universitas Andalas.

Wieringa, Sakia Eleonora, \& Setiawan), H. S. (Hersr. (1999). Penghancuran gerakan perempuan di-Indonesia. Garba Budaya.

Wieringa, Saskia Eleonora. (1999). Kultilanak Wangi : Organisasi-organisasi Perempuan Indonesia Sesudah 1950. Kalyanamitra.

Yati, R. M. (2017). Lahirnya Pergerakan Perempuan Minangkabau Pada Awal Abad XX. Kafaah: Journal of Gender Studies, 7(2), 147-158.

Zed, M. dkk. (1998). Sumatera Barat di Panggung Sejarah 1945-1995. Pustaka Sinar Harapan.

Zed, Mestika. (2010). Dekade Pergolakan Daerah : Mendekati Isu-Isu Konflik Pusat-Daerah 
Serli Agustina, Siti Fatimah

Zulbainar: Perempuan Pejuang Masyarakat Marjinal sebagai Aktivis Gerwani (1961-1977)

dalam Perspektif Pembangunan Nasional Tahun 1950-an. Pusat Kajian Sejarah dan Budaya Ekonomi.

Zulbainar. (2018). wawancara prinbadi mengenai kiprah dan pengalaman penting Zulbainar dalam Gerwani pada 11 agustus. 